\title{
TECNOLOGIA ASSISTIVA CÃES-GUIA NO BRASIL: UMA AÇÃO POLÍTICA ORIENTADA À INCLUSÃO SOCIAL DE PESSOAS COM DEFICIÊNCIA VISUAL
}

\author{
GUÍA DE TECNOLOGÍA ASISTENTE PERROS EN BRASIL: UNA ACCIÓN \\ POLÍTICA GUIADA PARA LA INCLUSIÓN SOCIAL DE LAS PERSONAS CON \\ DISCAPACIDAD VISUAL
}

\section{GUIDE DOGS' ASSISTIVE TECHNOLOGY IN BRAZIL: A POLITICAL ACTION ORIENTED TOWARDS SOCIAL INCLUSION OF PEOPLE WITH VISUAL IMPAIRMENT}

\author{
Magali DIAS DE SOUZA ${ }^{1}$ \\ Luiz ALBERTO FERREIRA ${ }^{2}$ \\ Filomena Lucia Gossler RODRIGUES DA SILVA ${ }^{3}$
}

RESUMO: Este artigo possui como propósito apresentar a experiência de implantação e funcionamento do Centro de Formação de Treinadores e Instrutores de Cães-Guia no Instituto Federal Catarinense - Campus Camboriú. Para alcançar o proposto, contextualizamos e analisamos o modo como se estabeleceu a política governamental que visou a inclusão social de pessoas com deficiência e discutimos a Tecnologia Assistiva Cães-Guia, uma mobilidade alternativa de apoio a pessoas com deficiência visual, destacando seu impacto na vida dos usuários.

PALAVRAS-CHAVE: Tecnologia Assistiva. Cães-guia. Deficiência visual. Inclusão social.

RESUMEN: Este artículo tiene como objetivo presentar la experiencia de implementación y operación del Centro de capacitación para instructores e instructores de perros guía en el Instituto Federal de Santa Catarina - Campus Camboriú. Para lograr la propuesta, contextualizamos y analizamos cómo se estableció la política del gobierno dirigida a la inclusión social de las personas con discapacidad y discutimos la Assistive Technology Guide Dogs, una movilidad alternativa que apoya a las personas con discapacidad visual, destacando su impacto en la vida. de los usuarios.

PALABRAS CLAVE: Tecnología de asistencia. Perros guía. Discapacidad visual. Inclusión social.

ABSTRACT: This article aims to present the experience of implementation and operation of the Training Centre of Trainers and Instructors of guide dogs at the Catarinense Federal Institute - Campus Camboriú. In order to achieve the proposed, we contextualize and analyze

\footnotetext{
${ }^{1}$ Instituto Federal de Educação, Ciência e Tecnologia Catarinense (IFC), Blumenau - SC - Brasil. Professora. ORCID: https://orcid.org/0000-0002-6793-6220. E-mail: magali.souza@ifc.edu.br

${ }^{2}$ Instituto Federal de Educação, Ciência e Tecnologia Catarinense (IFC), Blumenau - SC - Brasil. Professor. ORCID: https://orcid.org/0000-0002-2356-1172. E-mail: luiz.ferreira@ifc.edu.br

${ }^{3}$ Instituto Federal de Educação, Ciência e Tecnologia Catarinense (IFC), Blumenau - SC - Brasil. Professora. ORCID: https://orcid.org/0000-0002-8275-7714. E-mail: filomena.silva@ifc.edu.br
} 
how was established the government policy that aim at social inclusion of people with disabilities and we discussed Guide dogs' Assistive Technology, an alternative supporting mode for people with visual impairment, highlighting its impact on the lives of users.

KEYWORDS: Assistive technology. Guide dogs. Visual impairment. Social inclusion.

\section{Reflexões iniciais: e por falar em inclusão...}

Ao realizar uma retrospectiva histórica do atendimento às pessoas com deficiência $(\mathrm{PcD})$, constata-se que os modos de perceber esses sujeitos estão relacionados aos valores, culturas, concepções de sujeito de cada período. Desde os tempos dos povos mais primitivos até chegarmos à sociedade atual, vivenciamos momentos nos quais essas pessoas foram eliminadas, institucionalizadas ou segregadas, dependendo da perspectiva vigente.

Esses modos de agir passaram a ser questionados e ressoaram em movimentos mundiais em defesa das $\mathrm{PcD}$, muitos deles com incentivos governamentais, "que passaram a promover políticas públicas para eliminar formas de discriminação das pessoas com deficiência e reintegrá-las na sociedade" (LUIZ et al., 2019, p. 125), visando a igualdade de oportunidades e da equidade. Diante de tal percurso, entende-se que, se hoje se tem assegurado o direito à inclusão no Brasil, que corresponde ao exercício da cidadania, isso se deve às lutas, quando do processo de abertura política, tanto das PcD quanto da sociedade civil: familiares, pessoas simpatizantes com a causa, partidos políticos, sindicatos, associações voluntárias, associações corporativas e clubes, entre outros, que saíram em busca de conquistar espaços sociais, econômicos e de inclusão (CABRAL FILHO; FERREIRA, 2013).

No intuito de minimizar a exclusão e a desigualdade, decorrentes dos processos de eliminação, segregação e institucionalização das $\mathrm{PcD}$, no início do século XXI, diversos planos e programas governamentais explicitaram em seus planejamentos públicos a questão dos direitos humanos (BORGES; PEREIRA, 2016). No Brasil, por exemplo, foi promulgada, por meio do Decreto n. ${ }^{\circ}$ 6.949, de 25 de agosto de 2009, a Convenção Internacional sobre os Direitos das Pessoas com Deficiência e seu Protocolo Facultativo, assinada em 2007 na cidade de Nova York. Em 2011, foi lançado o Plano Nacional dos Direitos da Pessoa com Deficiência - o Viver sem Limite, pelo Decreto n. ${ }^{\circ}$ 7.612, que reafirmou o compromisso do País com as prerrogativas da Convenção promovida pela ONU (BRASIL, 2012). O Plano teve equivalência de emenda constitucional (BRASIL, 2013), sem perder de vista que a Constituição brasileira de 1988 também tem como balizadores os direitos humanos (BRASIL, 2006).

Composto por quatro eixos de atuação: acesso à educação, atenção à saúde, inclusão social e acessibilidade (BRASIL, 2011), o Plano Nacional Viver sem Limite (PNVSL) 
Tecnologia assistiva cães-guia no Brasil: uma ação política orientada à inclusão social de pessoas com deficiência visual

estabelece ações diferenciadas para cada um desses campos. Cabe-nos apresentar, neste artigo, o eixo relacionado à acessibilidade, mais especificamente a ação que previa a criação dos Centros Tecnológicos Cães-Guia. ${ }^{4}$

Tomando como referência os dados do Censo Brasileiro de 2010, o País tem cerca de 45,6 milhões de pessoas com algum tipo de deficiência. Destas, cerca de seis milhões têm grande dificuldade para enxergar e 528 mil são cegas. Levando-se em conta que, segundo estimativas das instituições de atendimento às pessoas com deficiência visual, há cerca de 150 cães-guia no País, é possível ter a dimensão da defasagem no atendimento às pessoas cegas no que se refere a esse tipo de Tecnologia Assistiva (TA) e da relevância da criação dos Centros Tecnológicos Cães-Guia.

\section{O percurso de criação dos Centros de Formação de Treinadores e Instrutores de Cães- Guia: a história do primeiro centro de formação brasileiro}

Dentre as metas estipuladas para o período de 2011 a 2014 no PNVSL, estava a criação de cinco Centros Tecnológicos de Formação de Treinadores e Instrutores de CãesGuia, alocados em Institutos Federais de Educação, Ciência e Tecnologia (IF). Os passos iniciais dados nessa direção, antes mesmo dessa ação governamental, foram percorridos no ano de 2008, por meio de uma atividade do Núcleo de Atendimento às Pessoas com Necessidades Específicas (Napne) do Instituto Federal Catarinense - Campus Camboriú (IFCCAM), que criou o "Projeto Cães-Guia". Na época, essa instituição constituía-se como um colégio agrícola ligado à Universidade Federal de Santa Catarina - UFSC (SOUZA, 2019). O projeto foi idealizado pela coordenadora do Napne da referida escola, que possuía uma atuação marcante na Ação TecNep/Programa Educação, Tecnologia e Profissionalização para Pessoas com Necessidades Educacionais Específicas da Secretaria de Educação Profissional e Tecnológica (Setec) e tencionou firmemente para sua concretização.

Somente após dois anos desse projeto inaugural, a Setec e a Secretaria Nacional de Promoção dos Direitos da Pessoa com Deficiência (SNPD) declararam apoio, incorporando-o como uma das ações do PNVSL (SOUZA; FERREIRA, 2015). Em 2012, o Ministério da Educação, disponibilizou recursos (Figura 1) para que fosse construído o primeiro Centro de Formação de Treinadores e Instrutores de Cães-Guia do Brasil (CFTICG), reconhecendo o esforço de trabalho realizado pelo grupo de servidores do IFC-CAM em prol da inclusão de

\footnotetext{
${ }^{4}$ Levando em consideração o eixo de acessibilidade, a gestão governamental brasileira estabeleceu também ações referentes ao Minha Casa, Minha Vida II, que previa a construção de casas adaptáveis; Programa Nacional de Inovação em Tecnologia Assistiva, constituído para apoiar o desenvolvimento de serviços, produtos, estratégias, práticas e metodologias inovadoras; Centro Nacional de Referência em Tecnologia Assistiva, designado para orientar núcleos de pesquisa; Crédito Facilitado para Aquisição de Produtos de Tecnologia Assistiva, uma linha de crédito para aquisição de produtos (BRASIL, 2013).
}

Doxa: Rev. Bras. Psico. e Educ., Araraquara, v. 21, n. 2, p. 362-373, jul./dez. 2019. 
pessoas com deficiência visual (PcDV), concretizando e edificando o espaço formativo tão desejado.

Figura 1 - Painel de informações - construção da estrutura física do CFTICG

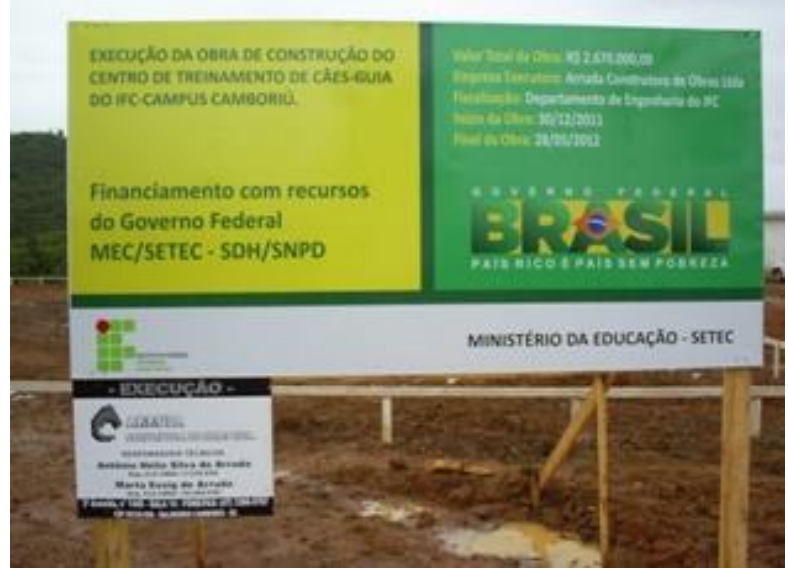

Fonte: Arquivo pessoal dos autores.

Inicialmente, foram liberados $\mathrm{R} \$ 3.140 .000,00$ para a execução da obra do CFTICG do IFC-CAM. Além desse recurso, outros R \$ 436.749,97 foram destinados para equipar as instalações. Posteriormente, a Secretaria dos Direitos Humanos da Presidência da República descentralizou recursos para cobrir a parte de custeio e construção do acesso ao Centro de Treinamento (CFTICG, 2017).

Concomitantemente ao andamento das obras, foram elaborados os procedimentos gerenciais pedagógicos e técnicos visando ao funcionamento do primeiro Curso de Treinador e Instrutor de Cães-Guia, o que exigiu grande esforço da equipe que foi sendo aglutinada à época, haja vista que se tratava de experiência inédita no País.

Afora esse IF, outros quatro foram selecionados por meio de chamada pública para alocar os centros previstos nas metas do PNVSL, sendo estes: o IF Sul de Minas - Campus Muzambinho; o IF Goiano - Campus Urutaí; o IF do Ceará - Campus Limoeiro do Norte; e o IF do Espírito Santo - Campus Alegre. Além desses, o IF do Amazonas - Campus Manaus e o IF de Sergipe - Campus São Cristóvão aderiram à proposição do Governo Federal (BRASIL, 2013).

Hoje, três desses centros estão concluídos e em plena condição de funcionamento, localizados nos Estados de Santa Catarina, Espírito Santo e Goiás. Com obras praticamente concluídas, aguardam repasse de recursos complementares para equipamento e custeio dos centros localizados em regiões do Amazonas, Ceará, Minas Gerais e Sergipe. Restrições orçamentárias ocorridas a partir do último ano fizeram com que o Campus Alegre paralisasse suas atividades após a formatura da primeira turma de Treinador e Instrutor de Cães-Guia. Pelas mesmas razões, os demais centros que ainda não haviam obtido condições para o início 
Tecnologia assistiva cães-guia no Brasil: uma ação política orientada à inclusão social de pessoas com deficiência visual

de suas atividades estudam destinar suas instalações para outros usos, caso o Governo Federal não venha a consolidar a política pública voltada para o cão-guia na Rede de Educação Profissional e Tecnológica.

\section{Formação Pública de Treinadores e Instrutores de Cães-Guia}

Quanto ao desenvolvimento da proposta, cabe destacar que os idealizadores do projeto pensaram, inicialmente, em criar um Centro de Treinamento de Cães-Guia, mas constataram que o País não contava com profissionais para atuar no treino dos cães e na instrução de duplas (pessoa com deficiência visual e cão-guia), ${ }^{5}$ pois somente três treinadores e instrutores atuavam em território nacional até o ano de 2012. De posse desse dado, foi preciso incorporar ao projeto inicial a questão da formação de pessoal para que os centros pudessem funcionar (SOUZA, 2019).

Por iniciativa organizacional, o IFC-CAM tornou-se, em 2012, a primeira instituição pública a oferecer a formação de Treinador e Instrutor de Cães-Guia, não só no Brasil, mas na América Latina (SOUZA et al., 2013). A falta de profissionais exigiu a criação de um curso específico para a formação dos servidores federais, docentes dos IFs, que trabalhariam nos outros centros a serem criados e habilitados. Para formar servidores públicos federais vindos de outros IFs, foi preciso criar uma estratégia institucional para que eles pudessem ser liberados de suas atividades profissionais em seus ambientes de trabalho. Tal estratégia consistiu na assinatura de um termo de cooperação técnica firmado entre os IFs de origem e o IFC durante o período destinado à formação para, posteriormente, esses profissionais retornarem às instituições de origem para gerenciar o funcionamento dos Centros de Treinamento do IF a que estavam vinculados.

Assim, foi criado um espaço formativo no qual o curso de Pós-Graduação lato sensu de Treinador e Instrutor de Cães-Guia (SOUZA; FERREIRA, 2018) oferta vagas conforme editais próprios. No princípio, o curso foi direcionado exclusivamente a servidores federais. O servidor candidato à vaga no curso deveria ter concluído curso de graduação e se submeter à prova escrita e entrevista, além de possuir Carteira Nacional de Habilitação $(\mathrm{CNH})$. Os processos seletivos de ingresso são regidos por edital próprio, elaborado por comissão eleita pelo Colegiado do Curso, composto por sua coordenação e professores (IFC-CAM, 2015). Nas duas primeiras turmas, foram oferecidas exclusivamente aos servidores (2012 e 2015). Em 2019, o curso foi aberto à comunidade e ingressaram, em sua maioria, pessoas sem vínculo com o serviço público federal, constituindo-se como uma turma mista. O processo

5 Disponível em: http://www.camboriu.ifc.edu.br/wp-content/uploads/2014/06/FOLDER-C\%C3\%83OGUIA.pdf.

Doxa: Rev. Bras. Psico. e Educ., Araraquara, v. 21, n. 2, p. 362-373, jul./dez. 2019 
seletivo dessa turma seguiu os mesmos critérios de ingresso, com exceção apenas da exigência da apresentação da habilitação para condução de veículos.

Ao longo do curso, os servidores-alunos e os alunos da comunidade em geral vão se constituindo como treinadores e instrutores. É papel do treinador preparar o cão para ser um guia e do instrutor orientar a adaptação da pessoa com deficiência visual ao cão-guia. Os âmbitos envolvidos nessa formação estão descritos na Figura 2:

Figura 2 - Âmbitos Formativos da Especialização em Treinadores e Instrutores de Cães-Guia do IFC-CAM
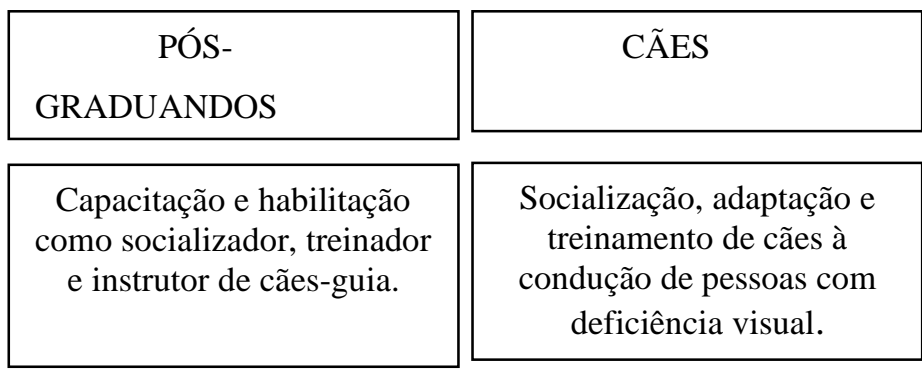

\begin{tabular}{|l|}
\hline PESSOAS COM \\
DEFICIÊNCIA \\
\hline $\begin{array}{c}\text { Instrução e capacitação de } \\
\text { pessoas com deficiência } \\
\text { visual a se tornar usuário } \\
\text { de cão-guia. }\end{array}$ \\
\hline
\end{tabular}

Fonte: Projeto Pedagógico do Curso (IFC-CAM, 2018).

Quanto ao âmbito formativo dos pós-graduandos, ao ingressar no curso, frequentam um total de 2.820 horas preenchidas com 28 disciplinas, que se organizam em aulas teóricas e práticas. Tanto a carga horária quanto a matriz curricular passaram por alterações, mas estas não modificaram as especificidades do curso ou dos componentes curriculares, que envolvem

[...] conhecimentos relativos às políticas públicas direcionadas às pessoas com deficiência e à administração e gerenciamento do Centro, assim como com conteúdos relacionados às particularidades do cão e ao seu treinamento, à adaptação das duplas, à orientação e mobilidade, ao recrutamento e seleção de usuários de cães-guia, ao acompanhamento em serviço e a sua aposentadoria. (NETTO et al., 2016).

São esses conhecimentos que vão conferir a qualificação necessária ao treinador e instrutor de cães-guia. Desde a primeira oferta do curso, as atividades seguem organizando-se em regime semestral, de forma presencial, em período integral (matutino e vespertino) de segunda à sexta-feira. A principal alteração realizada diz respeito à sua duração, que passou de dois anos, ofertados às turmas iniciadas em 2012 e 2015, para dois anos e meio para a turma recém-iniciada em 2019. Importa mencionar ainda que, de acordo com o Projeto Pedagógico do Curso, poderá, eventualmente, ocorrer um alongamento na duração do curso em razão de a dinâmica de seu funcionamento estar atrelada ao desenvolvimento do ciclo de produção dos animais. 
Tecnologia assistiva cães-guia no Brasil: uma ação política orientada à inclusão social de pessoas com deficiência visual

É preciso dizer que sem cães não existe um CFTICG; sem essa presença, não se cumpre o objetivo principal de um centro, que é entregar um cão-guia a uma pessoa com deficiência visual. Por isso, com relação ao âmbito formativo desses animais, referente ao seu preparo e treinamento, é preciso ter uma criação de cães para se constituir um plantel. O aluno pós-graduando, quando ingressa no curso, recebe um cão para socializar e iniciar sua formação nesse aspecto.

Para se chegar a essas condições, o IFC-CAM realizou um processo licitatório para que a primeira turma da especialização pudesse ser constituída. No tocante aos cães da segunda turma, eles foram gerados a partir de cinco matrizes e um reprodutor, selecionados dentre os animais da primeira turma. É nesse sentido que se trabalha na formação dos cães, pois entregam-se filhotes aos socializadores que iniciam a capacitação desse animal para ser um cão-guia.

O socializador e/ou família socializadora são aqueles que se prontificam a permanecer com o cão, desde filhote, por aproximadamente 15 meses (SOUZA et al., 2013). Tem a responsabilidade de promover o convívio social desse animal, conduzi-lo aos mais variados lugares, devido à necessidade de sua futura função que lhe exigirá que frequente qualquer ambiente e enfrente situações adversas.

São voluntários que realizam tal ação, iniciada pelo preenchimento de Ficha Cadastral disponível na página do IFC-CAM. ${ }^{6}$ De posse desse formulário, a instituição entrará em contato com os voluntários cadastrados quando houver filhotes de cães para serem alocados. Após a seleção de uma família socializadora, afirma-se contrato de trabalho voluntário e iniciam-se as atividades com a entrega de um filhote e fornecimento de todos os subsídios necessários de forma gratuita, com acompanhamento sistemático por treinadores, instrutores e alunos do IFC-CAM.

Depois de concluído o tempo de permanência na família socializadora, o cão volta ao Centro para finalizar seu treinamento, com duração de quatro a seis meses, com a perspectiva de que forme, futuramente, uma dupla com uma PcDV. A formação do cão vai desde o seu nascimento até sua entrega para o usuário, passando nesse período pela socialização, adaptação e treinamento à condução como guia. O processo estende-se pelo mesmo período que a formação dos alunos do curso.

É importante mencionar que nem todo cão treinado estará apto a ser um cão-guia. Quando se chega a essa constatação, o animal é desligado do programa e encaminhado à adoção. O desligamento pode ocorrer por problemas de saúde ou aspectos comportamentais do cão incompatíveis com as atividades da PcDV.

6 Disponível em: www.camboriu.ifc.edu.br/wp-content/uploads/2014/06/Cadastrado-Projeto-C\%C3\%A3oguia.docx. 
No que diz respeito ao âmbito formativo de pessoas com deficiência, a formação da dupla usuário-cão-guia costuma levar um tempo estimado em quatro semanas. Nas primeiras três, o possível usuário fica instalado em um alojamento que também compõe o CFTIGC, em regime de internato. Na última semana, a formação da PcDV é realizada no lugar onde mora, sempre acompanhado de um Instrutor do IFC-CAM. É essa etapa final que habilita a PcDV a receber seu animal, assim como um cão é considerado apto ao trabalho de guia quando é realizada com sucesso sua adaptação com esse usuário.

Tendo esse êxito na formação da dupla, ocorre uma cerimônia oficial de entrega do cão-guia e da constituição da dupla. É nesse ato simbólico que se formaliza a graduação do cão que se forma guia e da PcDV em usuário dessa Tecnologia Assistiva. Esse momento constitui-se como o evento oficial de recebimento do cão-guia pelo usuário, e ocorre em cerimônia pública, na qual a PcDV assina um termo de outorga do animal, que permanece patrimônio do IFC-CAM.

\section{Tecnologia Assistiva Cães-Guia}

A experiência humana é modulada pela tecnologia, produzida com as máquinas, que "integram-se ao funcionamento social, formando matrizes sociais, econômicas e políticas, atravessando as redes de sociabilidade e produzindo novas formas de estar no mundo e, consequentemente, novos sentidos para a vida" (NEVES; FONSECA, 2010, p. 79). A partir de uma visão social, Passerino (2011) afirma que a tecnologia não é um mero instrumento, mas um elemento inserido num processo social, atuando como mediadora de desenvolvimento humano.

As tecnologias assistivas emergem de estudos científicos na área de conhecimento da Tecnologia Assistiva, enquanto área multidisciplinar que envolve estudos, produtos e pesquisas que visam promover a qualidade de vida e a inclusão social (SANTAROSA et al., 2010) de pessoas com limitações funcionais permanentes ou temporárias - entre estas, as pessoas com deficiência. Constituiu-se a partir de estudos terapêuticos relacionados à área da saúde e, por conseguinte, decorrente dos conhecimentos médico-clínicos. Talvez por isso seja reconhecida como uma área técnica na qual prevalecem as questões de engenharia, desenvolvimento ou terapêuticas (ANDRADE; PEREIRA, 2009). Ao considerar-se essa área de conhecimento, deve-se abordá-la levando em conta sua complexidade e o caráter interdisciplinar que possui. O Comitê de Ajudas Técnicas (CAT) e a Coordenadoria Nacional para a Integração da Pessoa com Deficiência (Corde) conceituam a Tecnologia Assistiva como 
[...] uma área de conhecimento, de característica interdisciplinar, que engloba produtos, recursos, metodologias, estratégias, práticas e serviços que objetivam promover a funcionalidade, relacionada à atividade e participação, de pessoa com deficiência, incapacidades ou mobilidade reduzida, visando sua autonomia, independência, qualidade de vida e inclusão social. (BRASIL, 2007).

Composta por recursos (produtos, programas e equipamentos), estratégias e serviços (da área da saúde, engenharia e educação, entre outros) que abrangem o uso de artefatos no desempenho de atividades que apresentariam restrições de realização, a partir da TA busca-se a resolução de problemas funcionais apresentados pelas pessoas nessa condição (ALVES et al., 2006). Portanto, subdivide-se em áreas distintas: (1) os recursos pedagógicos adaptados; (2) a comunicação alternativa e aumentativa; (3) os recursos de acessibilidade ao computador; (4) os recursos para as atividades de vida diária; (5) as adaptações de atividades escolares, jogos e brincadeiras; (6) os auxílios para pessoas com deficiência visual e pessoas com deficiência auditiva; (7) o controle de ambiente; (8) a adequação postural; (9) a mobilidade alternativa; (10) as órteses e próteses; e (11) os projetos arquitetônicos para acessibilidade (BERSCH; PELOSI, 2006).

No que diz respeito aos cães-guias, podemos aproximá-los da área relacionada à mobilidade alternativa, que se refere a recursos, equipamentos ou estratégias utilizadas para melhoria da orientação e mobilidade pessoal, entre os quais podemos destacar também o guia vidente, técnicas de autoproteção, bengalas, equipamentos eletrônicos acoplados a bengalas, andadores, muletas, bicicletas e scooters adaptadas, cadeiras de rodas manuais e motorizadas. Conta-se também com os acessórios e adaptações que possibilitam a uma pessoa com deficiência física dirigir um automóvel, facilitadores de embarque e desembarque - como elevadores para cadeiras de rodas, utilizados em carros particulares e em transporte coletivo -, rampas para cadeiras de rodas, serviços de autoescola para pessoas com deficiência motora ou sensorial.

A TA é uma área de conhecimento que busca a promoção e facilitação na realização de atividades cotidianas, assim como promove a autonomia e independência de pessoas com dificuldades sensoriais, entre outras. Para que isso ocorra, lança mão de metodologias e estratégias que potencializam capacidades funcionais, vindo a responder a um momento e um lugar de necessidade de uso. Ao utilizar um cão-guia, a PcDV tem potencializada sua capacidade de orientação e mobilidade, o que lhe possibilita a interação e inclusão social, dando-lhe oportunidades, propiciando trocas, promovendo a participação e cidadania.

É pelo depoimento dos usuários de cães-guia que mais podemos nos aproximar do significado dessa parceria: 
Quando, pela primeira vez, tive a oportunidade de locomover-me com o Mambo, um Golden Retriever legítimo, extremamente carinhoso e com uma personalidade cativante, o êxtase era tanto que mal sentia meus pés tocando o chão. A sensação do vento chocando-se com meu rosto, devido a uma marcha dinâmica e veloz, a sensação de ziguezaguear pela calçada com desenvoltura, transpondo os obstáculos, a sensação de perceber a presença de postes, muro e árvores, por meio da "sombra sensorial" que eles emitem, sem necessitar tocá-los, foi, de fato, algo que, além de ser um divisor de águas na minha relação com a locomoção independente, também, mal sabia eu, que seria uma transformação da minha essência enquanto pessoa (TILLMANN, 2019, p. 218 - grifos no original).

Fica aqui o reconhecimento aos precursores desse projeto, que presentemente se constitui como ação, e àqueles que até hoje deram condições objetivas para sua manutenção, como direção do campus e reitoria. Ao instituir o preparo de multiplicadores em sete Centros de Formação de Treinadores e Instrutores de Cães-Guia na Rede Federal de Ensino Básico, Técnico e Tecnológico, o Brasil assumiu posição de destaque no fomento tecnológico nessa área, quando previu no PNVSL a formação de 25 treinadores e instrutores e de 150 duplas (BRASIL, 2013).

Em que pese a situação dos Centros de Formação de Treinadores e Instrutores de Cães-Guia na Rede Federal de Ensino Básico, Técnico e Tecnológico no IFC, temos essa política contemplada no Plano de Desenvolvimento Institucional do IFC. O grande desafio que se coloca neste momento consiste em consolidar esse programa como política pública de Estado pela Setec e pela SNPD, o que contribuirá para que haja garantia de seu financiamento.

\section{REFERÊNCIAS}

ALVES, D. O. et al. Sala de recursos multifuncionais: espaços para atendimento educacional especializado. Brasília: MEC; SEESP, 2006.

ANDRADE, V. S.; PEREIRA, L. S. M. Influência da tecnologia assistiva no desempenho funcional e na qualidade de vida de idosos comunitários frágeis: uma revisão bibliográfica. Revista Brasileira de Geriatria e Gerontologia, Rio de Janeiro, v. 12, n. 1, p. 113-122. 2009. Disponível em: http://dx.doi.org/10.1590/1809-9823.2009120110. Acesso em: 13 maio 2019.

BERSCH, R. C. R; PELOSI, M. B. Portal de ajudas técnicas para educação: equipamento e material pedagógico para educação, capacitação e recreação da pessoa com deficiência física. Tecnologia Assistiva: recursos de acessibilidade ao computador II. Brasília: ABPEE; MEC; SEESP, 2006.

BORGES, J. A. S.; PEREIRA, A. C. C. O estado da arte sobre políticas públicas para pessoas com deficiência no Brasil: dialogando sobre transversalidade e educação. Revista do Serviço 
Público, Brasília, v. 67, n. 4, p. 555-574, out./dez. 2016. Disponível em:

https://revista.enap.gov.br/index.php/RSP/article/view/1132/783. Acesso em: 11 maio 2019.

BRASIL. Constituição da República Federativa do Brasil, de 5 de outubro de 1988. 25. ed. São Paulo: NDJ, 2006.

BRASIL. Secretaria Especial dos Direitos Humanos. Coordenadoria Nacional para Integração da Pessoa Portadora de Deficiência - CORDE - Comitê de Ajudas Técnicas. Tecnologia Assistiva 2007. Disponível em:

http://www.mj.gov.br/sedh/ct/corde/dpdh/corde/comite_at.asp. Acesso em: 22 ago. 2007.

BRASIL. Decreto Legislativo n. ${ }^{\circ}$ 186, de 9 de julho de 2008. Aprova o texto da Convenção sobre os Direitos das Pessoas com Deficiência e de seu Protocolo Facultativo, assinados em Nova York, em 30 de março de 2007. Disponível em:

https://www2.camara.leg.br/legin/fed/decleg/2008/decretolegislativo-186-9-julho-2008577811-publicacaooriginal-100742-pl.html. Acesso em: 11 maio 2019.

BRASIL. Decreto n. ${ }^{\circ}$ 6.949, de 25 de agosto de 2009. Promulga a Convenção Internacional sobre os Direitos das Pessoas com Deficiência e seu Protocolo Facultativo, assinados em Nova York, em 30 de março de 2007. Disponível em:

http://www.planalto.gov.br/ccivil_03/_ato2007-2010/2009/decreto/d6949.htm. Acesso em: 11 maio 2019.

BRASIL. Decreto n. ${ }^{0}$ 7.612, de 17 de novembro de 2011. Institui o Plano Nacional dos Direitos da Pessoa com Deficiência - Plano Viver sem Limite. Disponível em:

http://www.planalto.gov.br/ccivil_03/_ato2011-2014/2011/decreto/d7612.htm. Acesso em: 11 maio 2019.

BRASIL. Secretaria de Direitos Humanos. Secretaria Nacional de Promoção dos Direitos das Pessoas com Deficiência. Convenção sobre os Direitos das Pessoas com Deficiência: Protocolo Facultativo à Convenção sobre os Direitos das Pessoas com Deficiência: Decreto Legislativo n. ${ }^{\circ}$ 186, de 9 de julho de 2008: Decreto n. ${ }^{\circ}$ 6.949, de 25 de agosto de 2009. 4. ed. rev. e atual. Brasília: Secretaria de Direitos Humanos, 2012.

BRASIL. Secretaria de Direitos Humanos da Presidência da República. Secretaria Nacional de Promoção dos Direitos das Pessoas com Deficiência. Viver sem limite - Plano Nacional dos Direitos da Pessoa com Deficiência. Brasília: SDH-PR; SNPD, 2013.

CABRAL FILHO, A. V.; FERREIRA, G. Movimentos sociais e o protagonismo das pessoas com deficiência. SER Social, Brasília, v. 15, n. 32, p. 93-116, jan./jun. 2013.

CFTICG - CENTRO DE FORMAÇÃO DE TREINADORES E INSTRUTORES DE CÃESGUIA. Relatório de produção técnica, pedagógica e administrativa do Centro de Formação de Treinadores e Instrutores do IFC - Campus Camboriú - Período 20112017. Camboriú, mar. 2017.

IFC-CAM - INSTITUTO FEDERAL CATARINENSE-CAMPUS CAMBORIÚ. Projeto Pedagógico do Curso de Pós-Graduação lato sensu, em nível de especialização, de Treinador e Instrutor de Cães-Guia. Camboriú: IFC-CAM, 2015.

IFC-CAM - INSTITUTO FEDERAL CATARINENSE-CAMPUS CAMBORIÚ. Projeto Pedagógico do Curso de Pós-Graduação lato sensu, em nível de especialização, de Treinador e Instrutor de Cães-Guia. Camboriú: IFC-CAM, 2018. 
LUIZ, L. C. et al. "Projeto Cães-guia": custos para implantação de um centro de formação de treinadores e instrutores de cães-guia. In: SOUZA, M. S. et al. (Org.). Cães-guia no Brasil: primeiros estudos. Rio de Janeiro: Letra Capital, 2019. p. 125-148.

NETTO, R. G. F. et al. A emergência de uma nova profissão no Brasil: treinador e instrutor de Cães-guia. 8. ${ }^{\text {a }}$ Jornada Científica e Tecnológica e 5. ${ }^{\circ}$ Simpósio de Pós-Graduação do IF Sul de Minas. Passos, 2016.

NEVES, J. M. D.; FONSECA, T. M. G. Devires contemporâneos: mutações do homem, do trabalho, e da tecnologia. Revista Informática na Educação: Teoria e Prática, Porto Alegre, v. 13, n.1, p. 75-90, jan./jun. 2010.

PASSERINO, L. M. Salas de recursos, tecnologias assistivas e processos de inclusão escolar a partir da perspectiva sócio-histórica. In: MORAES, S. C. (Org.). Educação inclusiva: diferentes significados. Porto Alegre: Evangraf, 2011. p. 67-77.

SANTAROSA, L. M. C. et al. Tecnologias digitais acessíveis. Porto Alegre: JSM Comunicação, 2010.

SOUZA, M. S. et al. Perfil das famílias socializadoras do Projeto Cães-Guia do IFC-Campus Camboriú. Anais do 31. Seminário de Extensão Universitária da Região Sul (SEURS). Florianópolis, 2013.

SOUZA, M. S. et al. Introdução. In: SOUZA, M. S. et al. (Org.). Cães-guia no Brasil: primeiros estudos. 1ed. Rio de Janeiro: Letra Capital, 2019. p. 11-14.

SOUZA, M. S.; FERREIRA, L. A. Projeto cães-Guia do IFC - Campus Camboriú: perfil das famílias socializadoras. Anais do II Congresso Nacional de Educação (CONEDU). Campina Grande, 2015.

SOUZA, M. S.; FERREIRA, L. A. A tecnologia assistiva cães-guia no Brasil: uma ação do Programa Viver sem Limite. Revista Observatório, Palmas, v. 4, n. 3, p. 307-336, maio 2018. Disponível em: https://doi.org/10.20873/uft.2447-4266.2018v4n3p307. Acesso em: 11 maio 2019.

TILLMANN, L. Um cão, 4patas, várias mudanças: relatos sobre a unidade usuário/cão-guia, a partir das perspectivas daqueles que seguram o arreio. In: SOUZA, M. S. et al. (Org.). CãesGuia no Brasil: primeiros estudos. Rio de Janeiro: Letra Capital, 2019. p. 215-232.

\section{Como referenciar este artigo}

Dias de SOUZA, Magali; FERREIRA, Luiz Alberto; RODRIGUES DA SILVA, Filomena Lucia Gossler. Tecnologia assistiva cães-guia no Brasil: uma ação política orientada à inclusão social de pessoas com deficiência visual. Doxa: Rev. Bras. Psico. e Educ., Araraquara, v. 21, n. 2, p. 362-373, jul./dez. 2019. e-ISSN: 2594-8385. DOI: https://doi.org/10.30715/doxa.v21i2.13165

Submetido em: 20/02/2019

Aprovado em: 20/07/2019

Publicado em: 01/08/2019 